\title{
Evaluasi Kinerja PT Bank Sumsel Babel Cabang Baturaja Menggunakan Balanced Scorecard
}

\author{
Mursalin \\ Akuntansi, F. Ekonomi dan Bisnis UPGRI Palembang, mursalin@univpgri-palembang.ac.id
}

\begin{abstract}
ABSTRAK
Penelitian ini bertujuan untuk menilai kinerja PT Bank Sumsel Babel Cabang Baturaja menggunakan Balanced Scorecard. Terdapat empat perspektif yang diukur dalam Balanced Scorecard yaitu: Perspektif Keuangan, Perspektif Pelanggan, Perspektif Proses Bisnis Internal serta Perspektif Pembelajaran dan Pertumbuhan. Dari hasil penelitian dapat diketahui bahwa Perspektif Keuangan berupa Return On Asset (ROA) mencapai 8,58\% yang menunjukkan kategori baik, Capital Adequency Ratio (CAR) mencapai 20,46\% yang juga menunjukkan kategori baik, Loan to Deposit Ratio (LDR) mencapai $1,41 \%$ yang menunjukkan kategori kurang baik, Kualitas Aset Produktif (KAP) mencapai 1,44\% yang dinyatakan baik, dan juga Efisiensi Operasional (BOPO) 48,15\% dengan kategori baik. Untuk Perspektif Pelanggan Market Share mencapai nilai 3 dengan kategori baik, namun bank harus lebih meningkatkan Customer Acquisition yang dalam penelitian ini mencapai nilai 1 artinya kurang baik. Perspektif Proses Bisnis Internal menunjukkan Service Error Rate dengan nilai 2 artinya cukup baik dan jarang terjadinya kesalahan dalam pelayanan. Kemudian, Perspektif Pembelajaran dan Pertumbuhan menunjukkan Retensi Karyawan mencapai nilai 2 juga dengan kategori cukup baik, ini berarti menujukkan peningkatan produktivitas karyawan selama tiga tahun yang menghasilkan kategori cukup baik.
\end{abstract}

Kata kunci : Evaluasi Kinerja, Balanced Scorecard.

\begin{abstract}
ABSTRACK
This study aims to assess the performance of PT Bank Sumsel Babel Baturaja Branch using the Balanced Scorecard. There are four perspectives measured in the Balanced Scorecard: Financial Perspective, Customer Perspective, Internal Business Process Perspective and Learning and Growth Perspective. From the results of the study it can be seen that the Financial Perspective in the form of Return On Assets (ROA) reached $8.58 \%$ which showed a good category, Capital Adequency Ratio (CAR) reached $20.46 \%$ which also showed a good category, Loan to Deposit Ratio (LDR) reached $1.41 \%$ which shows the unfavorable category, Earning Assets Quality (KAP) reached $1.44 \%$ which was declared good, and also Operational Efficiency (BOPO) $48.15 \%$ with good category. For the Market Share Customer Perspective reaching a value of 3 with a good category, but banks must further improve the Customer Acquisition which in this study reached a value of 1 means that it is not good. The Internal Business Process Perspective shows that the Service Error Rate with a value of 2 means that it is quite good and rarely errors in service. Then, the Learning and Growth Perspective shows that Employee Retention reaches a value of 2 also with a pretty good category, this means showing an increase in employee productivity over three years which results in a pretty good category.
\end{abstract}

Keywords: Performance Evaluation, Balanced Scorecard.

\section{A. PENDAHULUAN}

Penilaian kinerja memegang peranan penting dalam suatu perusahaan, organisasi, instansi baik itu instansi pemerintah maupun swasta dikarenakan dengan dilakukannya penilaian kinerja dapat diketahui efektivitas dari penerapan suatu strategi dan penerapannya dalam kurun waktu tertentu. Penilaian kinerja dapat mendeteksi kelemahan atau kekurangan yang terdapat dalam perusahaan, untuk selanjutnya dilakukan perbaikan dimasa 
mendatang.Balanced Scorecard terdiri Perspektif Keuangan, Perspektif Pelanggan, Perspektif Proses Bisnis Internal, serta Perspektif Pembelajaran dan Pertumbuhan.

Kondisi yang mendukung kelayakan penerapan Balanced Scorecard pada suatu perusahaan yaitu perusahaan memiliki visi dan misi yang jelas dan mudah dipahami sehingga menentukan konsep strategi yang harus dilaksanakan untuk mencapai tujuan perusahaan, perusahaan harus memiliki struktur organisasi dan pembagian tugas sehingga hubungan antar lini organisasi berjalan dengan baik, kondisi persaingan yang semakin meningkat, dan perusahaan memiliki sumber daya manusia yang berkualitas.

PT Bank Sumsel Babel Cabang Baturaja dalam melakukan penilaian kinerja dengan hanya menilai ukuranukuran keuangan saja. Perhatian manajer hanya terfokus pada kinerja keuangan dan bagaimana mencari nasabah sebanyak-banyaknya. Sehingga kinerja bank dari segi non keuangan lainnya, yaitu; Perspektif Pelanggan seperti respon karyawan dalam menanggapi masalah terhadap nasabah dan tingkat kepuasan nasabah belum dapat diketahui baik tidaknya; Perspektif Proses Bisnis Internal seperti bagaimana bank dapat memberikan jasa secara efisien dan efektif, untuk mengetahui seberapa baik bisnis mereka berjalan dan apakah jasa mereka sesuai dengan spesifikasi nasabah; Perspektif Pembelajaran dan Pertumbuhan ini menekankan pada bagaimana bank dapat berinovasi, terus tumbuh dan berkembang agar dapat bersaing dimasa sekarang dan dimasa akan datang. Padahal komponen tersebut yang dapat meningkatkan kepercayaan nasabah terhadap pelayanan perusahaan yang sangat menentukan keberhasilan perusahaan dalam jangka panjang.

Berdasarkan latar belakang tersebut, maka penulis melakukan penelitian dengan judul "Evaluasi Kinerja PT Bank Sumsel Babel Cabang Baturaja Menggunakan Balanced Scorecard".

\section{B. KAJIAN TEORI}

1) Pengertian

Scorecard

Menurut Mulyadi (2009:1)

Balanced Scorecard merupakan alat manajemen kontemporer yang didesain untuk meningkatkan kemampuan perusahaan/organisasi dalam melipatgandakan kinerja keuangan luar biasa secara berkesinambungan (sustainable outstanding financial performance).

Menurut Hansen dan Mowen (2009:366)Balanced Scorecard merupakan suatu sistem manajemen strategis atau lebih tepat dinamakan suatu "Strategic Based Responsibility Accounting System", yang menjabarkan misi dan strategi suatu organisasi ke dalam tujuan operasional dan tolak ukur kinerja untuk empat perspektif yang berbeda, yaitu Perspektif Keuangan, Perspektif Pelanggan, Perspektif Proses Bisnis Internal, serta Perspektif Pembelajaran dan Pertumbuhan.

\section{2) Tujuan Balanced Scorecard}

Menurut Abdul(2009:209) tujuan Balanced Scorecard adalah sebagai alat dalam memfokuskan organisasi, meningkatkan komunikasi, menetapkan tujuan organisasi, dan menyediakan umpan balik bagi manajemen.

Menurut Sony, dkk (2010:128) tujuan Balanced Scorecard yaitu untuk menciptakan partisipasi dan komunikasi mengenai visi dan tujuan strategi suatu perusahaan. 


\section{3) Perspektif dalam Balanced Scorecard}

Menurut Abdul (2009:209) aspekaspek yang diukur dalam Balanced Scorecard antara lain :

1. Perspektif Keuangan

Perspektif Keuangan adalah suatu sistem pengukuran kinerja keuangan dengan menggunakan aspek keuangan dalam memperoleh laba dan nilai pasar. Ukuran keuangan biasanya diwujudkan dalam rentabilitas dan pertumbuhan. Hal ini sangat beralasan karena ukuran keuangan merupakan suatu ikhtisar dari konsekuensi ekonomi yang terjadi yang disebabkan oleh keputusan dan tindakan ekonomi yang telah diambil.

Menurut Veithzal dan Arviyan (2010:848) dalam Perspektif Keuangan ini memerlukan alat ukur yaitu rasio. Rasio merupakan alat ukur untuk menganalisis atau mengukur tingkat rentabilitas yang dicapai oleh bank. Selain untuk mengukur kinerja, rasiorasio dalam kategori ini dapat digunakan untuk mengukur tingkat kesehatan bank, yaitu:

$>$ Rentabilitas

Menurut Veithzal dan Arviyan (2010:865) Rasio Rentabilitas atau Earning menggambarkan kemampuan bank dalam meningkatkan labanya melalui semua kemampuan dan sumber yang ada sehingga diketahui mengukur tingkat efisiensi usaha dan rentabilitas bank yang dicapai oleh bank tersebut.

Rasio yang digunakan adalah Return on Total Assets (ROA). ROA merupakan rasio yang digunakan untuk mengukur keberhasilan manajemen dalam menghasilkan laba secara keseluruhan dengan cara membandingkan antara laba sebelum pajak dengan total aset. ROA juga menggambarkan perputaran aset yang diukur dari volume penjualan. Semakin besar ROA suatu bank, maka semakin besar pula tingkat keuntungan yang dicapai bank tersebut dan semankin baik pula posisi bank tersebut dari penggunaan aset. Semakin kecil rasio ini mengindikasikan kurangya kemampuan manajemen bank dalam hal mengelola aset untuk meningkatkan pendapatan atau menekan biaya.

Berikut formulanya adalah :

$\mathrm{ROA}=\frac{\text { Labasebelumpajak }}{\text { TotalAset }} \times 100 \%$

Permodalan

Menurut Veithzal dan Arviyan (2010:850) permodalan merupakan analisis yang digunakan untuk mengukur kewajiban penyediaan modal minimum bank maupun dalam memenuhi kewajiban jangka panjang atau kemampuan bank untuk memenuhi kewajiban-kewajiban jika terjadi likuidasi. Rasio yang digunakan untuk mengukur kecukupan modal bank yaitu dengan menggunakan Capital Adequency Ratio (CAR). Rasio CAR ini digunakan untuk mengukur kecukupan modal yang dimiliki bank untuk menilai keamanan dan kesehatan bank dari sisi modal pemiliknya. Semakin tinggi risiko CAR, maka semakin baik kinerja bank tersebut.

Ketentuan pemenuhan modal (Capital Adequency Ratio) yang memadai bertujuan untuk menjaga likuiditas bank dan untuk menghindari penyaluran pembiayaan tanpa memliki pertimbangan yang tepat apalagi terhadap institusi atau individu yang memilik afiliasi dengan bank yang bersangkutan.

Berikut rumusnya adalah :

$$
\mathrm{CAR}=\frac{\text { Modalsendiri }}{\text { ATMR }} \times 100 \%
$$

a. Likuiditas

Menurut Veithzal dan Arviyan (2010:870) penilaian likuiditas merupakan penilaian terhadap 
kemampuan bank dalam memelihara dan memenuhi kebutuhan likuiditas yang memadai dan kecukupan manajemen risiko likuiditas. Bank dikatakan likuid apabila mempunyai alat pembayaran berupa aset lancar lebih besar dibandingkan dengan seluruh kewajibannya sehingga dapat memenuhi semua utang-utangnya.

Rasio yang digunakan adalah Loan to Deposit Ratio (LDR). Rasio ini menyatakan seberapa jauh kemampuan bank dalam membayar kembali penarikan dana yang dilakukan deposan dengan mengandalkan kredit yang diberikan.

Berikut rumusnya adalah :

LDR $=\frac{\text { Kredit yang diberikan }}{\text { Dana Pihak Ketiga }} \times 100 \%$

b. Kualitas Aset

Menurut Veithzal dan Arviyan (2010:857) tingkat kelangsungan usaha bank berkaitan erat dengan aset produktif yang dimilikinya, oleh karena itu bank dituntut untuk senatiasa dapat memantau dan menganalisis kualitas aset yang dimilikinya. Kualitas aset (assets quality) adalah menilai jenisjenis aset yang dimiliki oleh bank, agar sesuai dengan peraturan yang ditetapkan oleh Bank Indonesia dengan membandingkan antara Kualitas Aset Produktif (KAP) yang diklasifikasikan terhadap total aset produktif sehingga dapat diketahui tingkat kemungkinan diterimannya kembali dana telah ditanamkan pada suatu investasi/pembiayaan. Semakin kecil rasio KAP, maka semakin besar tingkat kemungkinan diterimannya kembali dana yang ditanamkan.

Berikut rumusnya adalah :

$\mathrm{KAP}=\frac{\text { Aset Produktif } \text { yang Diklasif ikasikan }}{\text { Total Aset Produktif }} \times 100 \%$

c. Efisiensi Operasional

Menurut Veithzal dan Arviyan (2010:202) penilaian aspek efisiensi dimaksudkan untuk mengukur kemampuan bank dalam memanfaatkan dana yang dimiliki dan biaya yang dilakukan untuk mengoperasikan dana tersebut. Efisiensi operasional bank diukur menggunakan BOPO. BOPO merupakan rasio efisiensi yang digunakan untuk mengukur tingkat efisiensi dan kemampuan bank dalam melakukan kegiatan operasinya.

Berikut rumusnya adalah :

BOPO $=\frac{\text { Biaya Operasional }}{\text { Pendapatan Operasional }} \times 100 \%$

2. Perspektif Pelanggan

Perspektif Pelanggan merupakan suatu sistem pengukuran yang mengukur kinerja perusahaan dalam hal memuaskan pelanggannya. Perspektif ini merupakan leading indicator, dimana perspektif pelanggan berfokus pada bagaimana organisasi atau perusahaan dapat memuaskan pelanggan. Kinerja yang buruk dari perspektif ini akan menurunkan jumlah pelanggan dimasa depan meskipun saat ini kinerja keuangan terlihat baik.

Tolak ukur dari Perspektif Pelanggan antara lain :

> Pangsa Pasar (Market Share)

Mengukur seberapa besar proporsi segmen pasar tertentu yang dikuasai oleh perusahaan.

MS $=\frac{\text { Jumlah Konsumen Terlayani }}{\text { Jumlah Konsumen }} \times 100 \%$

Resensi Pelanggan (Customer Resentation)

Mengukur berapa besar kemampuan perusahaan dalam mempertahankan pelanggan lama.

CR $=\frac{\text { Jumlah Pelanggan Lama }}{\text { Jumlah Total Pelanggan }} \times 100 \%$
Akuisisi Pelanggan (Customer
Acquitition)
Ukuran akusisi pelanggan yaitu
mengukur peningkatan r dan
pernurunan jumlah pelanggan yang
ada pada perusahaan serta


bermanfaat untuk melihat seberapa jauh masyarakat tertarik atau berminat dan percaya terhadap pelayanan jasa yang diberikan perusahaan.

$C A=\frac{\text { Jumlah Pelanggan Baru }}{\text { Jumlah Total Pelanggan }} \times 100 \%$

Tingkat Kepuasan Pelanggan (Customer Satisfaction) mengukur tingkat kepuasaan para pelanggan terhadap layanan perusahaan.

\section{Perspektif Proses Bisnis Internal}

Perspektif Proses Bisnis Internal merupakan suatu sistem pengukuran yang mengukur seberapa baik bisnis perusahaan berjalan. Dalam perspektif ini kinerja bank diukur dari bagaimana bank dapat memberikan jasa secara efesien dan efektif. Manajemen mengidentifikasi proses bisnis internal yang kritis yang harus diunggulkan dalam perusahaan perspektif ini untuk mengetahui seberapa baik bisnis mereka berjalan dan apakah produk atau jasa mereka sesuai dengan spesifikasi pelanggan.

Menurut Kaplan dan Norton (2010:83), membagi bisnis internal ke dalam tiga tahap :

Proses Inovasi

Dalam proses inovasi, perusahaan mengidentifikasi keinginan dan kebutuhan pasar baru, dan para pelanggan masa kini dan masa mendatang dengan cara merancang dan mengembangkan produk baru yang sesuai dan mampu memenuhi kebutuhan konsumen sehingga kedua hal tersebut merupakan hasil yang sangat penting dan tidak terpisahkan.

$>$ Proses Operasi

Proses operasi perusahaan mencerminkan aktivitas yang dilakukan perusahaan, mulai saat diterimanya order dari customer sampai dengan pada saat produk/jasa tersebut dikirim/diterima oleh pelanggan, adapun tolak ukur dalam pengukuran dan proses pembuatan produk/jasa adalah tingkat kerusakan para penjual, dan pengerjaan ulang (rework) serta waktu ketepatan pengiriman barang.

> Proses Pelayanan Purna Jual Dalam tahap ini perusahaan berupaya memberikan manfaat tambahan kepada pelanggan yang telah membeli produknya. Manfaat tambahan dapat berupa layanan purna transaksi jual beli. Dalam hal ini tolak ukur yang dapat digunakan adalah jangka waktu perbaikan kerusakan.

Tolak ukur dari perspektif proses bisnis internal antara lain Service Error Rate. Service Error Rate dimaksudkan untuk mengetahui tingkat pelayanan kesalahan yang diberikan oleh perusahaan kepada pelanggan. Service Error Rate diukur dengan cara membandingkan jumlah pelayanan kesalahan (Service Error) dengan jumlah kesalahan yang terjadi.

$$
\text { Service Error Rate }=\frac{\text { Jumlah Pelayanan Kesalahan }}{\text { Jumlah Kesalahan yang Terjadi }} \times 100 \%
$$

4. Perspektif Pembelajaran dan Pertumbuhan

Perspektif Pembelajaran dan Pertumbuhan merupakan suatu sistem pengukuran yang mengukur kinerja perusahaan dalam hal memperhatikan karyawannya. Perspektif ini menekankan pada bagaimana bank 
dapat berinovasi, terus tumbuh dan berkembang agar dapat bersaing dimasa sekarang maupun yang akan datang. Oleh karena itu sumber daya dituntut untuk produktif dan terus belajar agar mempunyai kemampuan dalam berinovasi. Tujuan perspektif ini adalah untuk mendorong perusahaan menjadi organisasi yang belajar (learning organization) sekaligus mendorong pertumbuhannya.

Menurut Kaplan dan Norton (2010:110), adapun tolak ukur dalam perspektif pembelajaran dan pertumbuhan antara lain:

> Kepuasan karyawan, mengukur tingkat kepuasan pelanggan terhadap jasa atau produk perusahaan.

$>$ Retensi karyawan, merupakan kemampuan perusahaan untuk mempertahankan selama mungkin pekerja yang diminati perusahaan. Rumus untuk mencari retensi karyawan sebagai berikut :

$$
\frac{\text { Jumlah Karyawan Keluar }}{\text { Total Jumlah Karyawan }} x 100 \%
$$

$>$ Produktivitas karyawan, untuk mengetahui produktivitas karyawan dalam periode tertentu.

4) Keunggulan

Balanced

\section{Scorecard}

Menurut Abdul (2009:217) keunggulan Balanced Scorecard sebagai metode pengukuran kinerja manajemen dibandingkan dengan pengukuran kinerja tradisional adalah :

1. Merupakan konsep pengukuran yang komprehensif. Balanced Scorecard menekankan pengukuran kinerja tidak hanya pada aspek kuantitatif saja, tetapi juga aspek kualitatif. Aspek finansial dilengkapi dengan aspek customer, inovasi dan pengembangan pasar merupakan fokus pengukuran integral. Keempat perspektif menyediakan keseimbangan antara pengukuran eksternal seperti laba dengan ukuran internal seperti pengembangan produk. Keseimbangan ini menunjukkan trade-offyang dilakukan oleh manajer terhadap ukuran-ukuran tersebut dan mendorong manajer untuk mencapai tujuan mereka di masa depan tanpa membuat tradeoff diantara kunci-kunci sukses tersebut. Melalui empat perspektif, balanced scorecard mampu memandang berbagai faktor lingkungan secara menyeluruh.

2. Merupakan konsep yang adaptif dan responsif terhadap lingkungan bisnis.

3. Memberikan fokus terhadap tujuan menyeluruh perusahaan atau bank.

\section{5) Kelemahan}

Balanced Scorecard

Menurut Abdul (2009:217) masalah-masalah berikut ini dapat mengurangi manfaat dari Balanced Scorecard, yaitu :

a. Kurang hubungan antara ukuran hasil keuangan dan hasil non keuangan. Tidak ada jaminan bahwa tingkat keuntungan masa depan akan mengikuti pencapaian target pada setiap bidang non keuangan.

b. Fixation on Financial Result. Pencapaian ukuran keuangan seringkali tidak dikaitkan dengan program insentif sehingga berpengaruh pada pencapaian target.

c. Tidak adanya mekanisme perbaikan. Seringkali perusahaan tidak memiliki mekanisme perbaikan jika ukuran-ukuran hasil tidak ada.

d. Ukuran-ukurannya tidak diperbarui. Banyak perusahaan tidak memiliki mekanisme formal 
untuk memperbarui ukuranukuran agar segaris dengan perubahan strategi. Hasilnya adalah perusahaan menghasilkan ukuran yang bedasarkan strategi sebelumnya.

e. Pengukuran terlalu berlebihan. Berapa kali ukuran kritis dapat dilakukan pada manajer tanpa kehilangan fokus.

f. Kesulitan dalam menentukan trade-off.
6) Balanced

Scorecard Berdasarkan Ketentuan Bank Indonesia

a) Perspektif Keuangan

Berdasarkan ketentuan Bank Indonesia (BI), bank yang dinyatakan termasuk bank yang sehat harus mempunyai standar pada masingmasing rasio keuangan yang kemudian dapat menjadi tolak ukur dalam pengukuran Perspektif Keuangan.

Berikut tabel standar pada masing-masing rasio keuangan bank (Perspektif Keuangan) yaitu:

Tabel Kriteria Rasio Keuangan Bank (Perspektif Keuangan)

\begin{tabular}{|l|l|c|c|}
\hline \multirow{2}{*}{ No } & \multicolumn{2}{|c|}{ Rasio Keuangan } & \multicolumn{2}{c|}{ Standar } \\
\cline { 3 - 4 } & & Baik & Kurang Baik \\
\hline 1 & Rasio Rentabilitas (ROA) & $>1 \%$ & $<1 \%$ \\
\hline 2 & Rasio Permodalan (CAR) & $>8 \%$ & $<8 \%$ \\
\hline 3 & Rasio Likuiditas (LDR) & $85 \%-100 \%$ & $<85 \%-100 \%$ \\
\hline 4 & Rasio Kualitas Aset Produktif (KAP) & $<5 \%$ & $>5 \%$ \\
\hline 5 & Rasio Efisiensi Operasional (BOPO) & $<95 \%$ & $>95 \%$ \\
\hline
\end{tabular}

Sumber : Bank Indonesia, 2012

b) Perspektif Pelanggan

Untuk menentukan standar dari Perspektif Pelanggan, yaitu :

Tabel Standar Perspektif Pelanggan

\begin{tabular}{|l|l|l|l|l|}
\hline No & \multicolumn{1}{|c|}{ Keterangan } & \multicolumn{1}{|c|}{$\begin{array}{c}\text { Interval } \\
\text { Pelanggan }\end{array}$} & \multicolumn{1}{|c|}{$\begin{array}{c}\text { Sobotandar } \\
\text { Nilai }\end{array}$} \\
\hline 1 & Market Share & $>50 \%$ & Baik & 3 \\
& & $\begin{array}{l}30 \%-50 \% \\
<30 \%\end{array}$ & $\begin{array}{l}\text { Cukup } \\
\text { Kurang Baik }\end{array}$ & 2 \\
& & & & 1 \\
2 & Customer & $>15 \%$ & Baik & 3 \\
& Acquisition & $10 \%-15 \%$ & Cukup & 2 \\
& & $<10 \%$ & Kurang Baik & 1 \\
\hline
\end{tabular}

Sumber : Bank Indonesia, 2012

c) Perspektif Proses Bisnis Internal

Untuk menentukan standar dari Perspektif Proses Bisnis Internal, yaitu :

Tabel Standar Perspektif Proses Bisnis Internal

\begin{tabular}{|l|l|l|l|l|}
\hline No & Keterangan & $\begin{array}{l}\text { Interval Proses } \\
\text { Bisnis Internal }\end{array}$ & Standar & $\begin{array}{l}\text { Bobot } \\
\text { Nilai }\end{array}$ \\
\hline 1 & Service Error & $>75 \%$ & Baik & 3 \\
& Rate & $\begin{array}{l}50 \%-75 \% \\
\text { Cukup }\end{array}$ & 2 \\
& & Kurang Baik & 1 \\
\hline
\end{tabular}

Sumber : Bank Indonesia, 2012 
d) Perspektif Pembelajaran dan Pertumbuhan yaitu :

Untuk menentukan standar dari Perspektif Pembelajaran dan Pertumbuhan,

Tabel Standar Perspektif Pembelajaran dan Pertumbuhan

\begin{tabular}{|l|l|l|l|l|}
\hline No & Keterangan & $\begin{array}{c}\text { Interval } \\
\text { Pembelajaran dan } \\
\text { Pertumbuhan }\end{array}$ & \multicolumn{1}{|c|}{ Standar } & \multicolumn{1}{|c|}{$\begin{array}{c}\text { Bobot } \\
\text { Nilai }\end{array}$} \\
\hline 1 & Retensi & $\begin{array}{l}<3 \% \\
3 \%-8 \%\end{array}$ & Baik & 3 \\
& Karyawan & Cukup & 2 \\
\hline
\end{tabular}

Sumber : Bank Indonesia, 2012

7) Kerangka Pemikiran

Menurut Sugiyono (2010:89) kerangka pemikiran merupakan sintesa tentang hubungan antar variabel yang disusun dari berbagai teori yang telah dideskripsikan. Pada bagian kerangka berfikir peneliti menguraikan pola pikirnya secara deduktif berdasarkan landasan teori yang terlampir dalam gambar 1 dibawah ini:

\section{Gambar Kerangka Pemikiran}

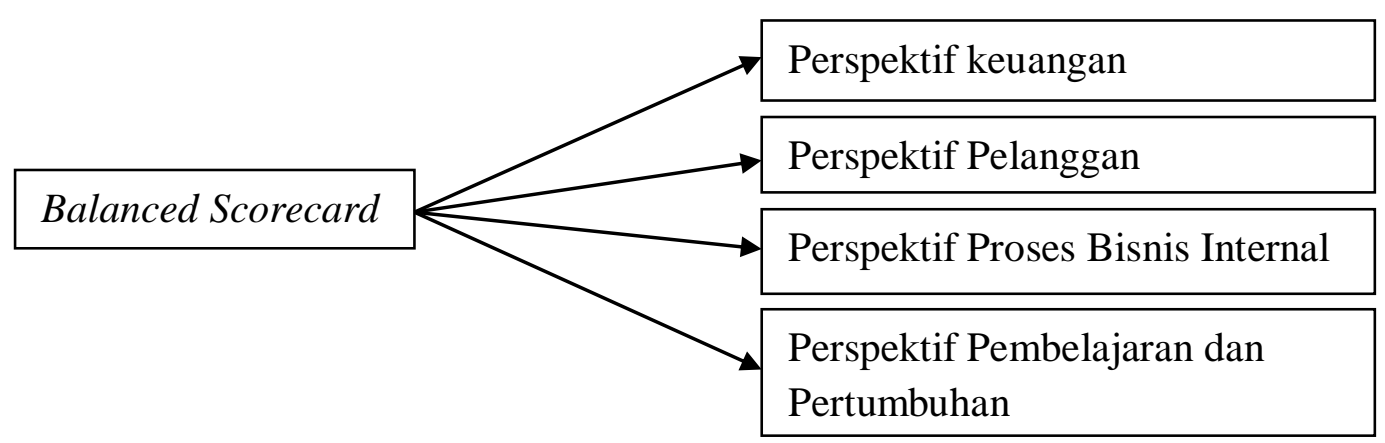

PT Bank Sumsel Babel Cabang Baturaja dalam melakukan penilaian kinerja dengan hanya menilai ukuranukuran keuangan saja. Oleh karena itu, Balanced Scorecard ini menyeimbangkan penggunaan ukuran kinerja keuangan dan non keuangan ketika mengevaluasi kinerja jangka pendek serta jangka panjang dalam sebuah laporan. Dalam penerapannya Balanced Scorecard terdiri dari empat perspektif, yaitu:Perspektif Keuangan, Perspektif Pelanggan, Perspektif Proses Bisnis Internal, serta Perspektif Pembelajaran dan Pertumbuhan.

\section{METODE PENELITIAN}

\section{1) Variabel Penelitian}

Menurut Sugiyono (2010:58) variabel penelitian adalah segala sesuatu yang berbentuk apa saja yang ditetapkan oleh peneliti untuk dipelajari sehingga diperoleh informasi tentang hal tersebut, kemudian ditarik kesimpulan. Variabel yang digunakan dalam penelitian ini adalah Balanced Scorecard.

\section{2) Populasi dan Sampel}

a. Populasi

Menurut Sugiyono (2010:115) populasi adalah wilayah generalisasi yang terdiri atas objek/subjek yang mempunyai kualitas dan karakteristik 
tertentu yang ditetapkan oleh peneliti untuk dipelajari dan kemudian ditarik kesimpulannya.

Populasi dalam penelitian ini adalah laporan keuangan, data nasabah, dan data karyawanpadaPT Bank Sumsel Babel Cabang Baturaja.

b. Sampel

Menurut Sugiyono (2010:116) sampel adalah bagian dari jumlah dan karakteristik yang dimiliki oleh populasi tersebut. Sampel yang digunakan dalam penelitian ini adalah laporan keuangan, data nasabah, dan data karyawan pada PT Bank Sumsel Babel Cabang Baturaja dari tahun 2016, 2017, dan 2018.

\section{3) Teknik Pengumpulan Data}

Data yang digunakan dalam penelitian ini adalah data sekunder. Teknik pengumpulan data yang digunakan adalah studi pustaka dan dokumetasi. Data dokumentasi yang diperlukan berupa laporan keuangan, data nasabah, dan data karyawanpada PT Bank Sumsel Babel Cabang Baturaja.

\section{4) Teknik Analisis Data}

Analisis data yang digunakan dalam penelitian ini adalah analisis dekriptif kuantitatif. Dengan menggunakan analisis deskriptif kuantitatif peneliti menggunakan data berupa angka-angka yang diperoleh dari PT Bank Sumsel Babel Cabang Baturaja dan selanjutnya diberikan uraian penjelasan tentang pengukuran kinerja bankmenggunakan Balanced Scorecard.

\section{HASIL PENELITIAN DAN PEMBAHASAN \\ 1) Perspektif Keuangan \\ $>$ Rasio Rentabilitas}

Berikut ini tabel Rasio Rentabilitas PT Bank Sumsel Babel Cabang Baturaja tahun 2016 s.d. 2018:

Tabel Rasio Rentabilitas

PT Bank Sumsel Babel Cabang Baturaja

Tahun 2016 s.d. 2018 (dalam jutaan rupiah)

\begin{tabular}{|l|c|c|c|}
\hline \multicolumn{1}{|c|}{ Keterangan } & Tahun 2016 & Tahun 2017 & Tahun 2018 \\
\hline Laba tahun berjalan & 36.907 & 29.596 & 22.968 \\
\hline Total aset & 352.925 & 337.333 & 349.173 \\
\hline \% ROA & $10,4 \%$ & $8,77 \%$ & $6,57 \%$ \\
\hline Rata-rata & $8,58 \%$ & & \\
\hline
\end{tabular}

Sumber : Data yang diolah, 2019

$>$ Rasio Permodalan

Berikut ini tabel Rasio Permodalan PT Bank Sumsel Babel Cabang Baturaja tahun 2016 s.d. 2018 :

Tabel Rasio Permodalan

PT Bank Sumsel Babel Cabang Baturaja

Tahun 2016 s.d. 2018 (dalam jutaan rupiah)

\begin{tabular}{|l|c|c|c|}
\hline \multicolumn{1}{|c|}{ Keterangan } & Tahun 2016 & Tahun 2017 & Tahun 2018 \\
\hline Modal sendiri & 1.589 .282 & 1.636 .559 & 1.741 .162 \\
\hline ATMR & 8.146 .880 & 8.146 .880 & 7.869 .109 \\
\hline$\%$ CAR & $19,5 \%$ & $20,1 \%$ & $21,8 \%$ \\
\hline Rata-rata & $20,46 \%$ & & \\
\hline
\end{tabular}

Sumber :Data yang diolah, 2019 
$>$ Rasio Likuiditas

Berikut ini adalah tabel Rasio Likuiditas PT Bank Sumsel Babel Cabang Baturaja tahun 2016 s.d. 2018 :

Tabel Rasio Likuiditas

PT Bank Sumsel Babel Cabang Baturaja

Tahun 2016 s.d. 2018 (dalam jutaan rupiah)

\begin{tabular}{|l|c|c|c|}
\hline \multicolumn{1}{|c|}{ Keterangan } & Tahun 2016 & Tahun 2017 & Tahun 2018 \\
\hline $\begin{array}{l}\text { Kredit yang } \\
\text { diberikan }\end{array}$ & 250.596 & 294.202 & 323.693 \\
\hline Dana pihak ketiga & 198.007 & 199.691 & 211.794 \\
\hline \%LDR & $1,26 \%$ & $1,47 \%$ & $1,52 \%$ \\
\hline Rata-rata & $1,41 \%$ & & \\
\hline
\end{tabular}

Sumber: Data yang diolah, 2019

$>$ Rasio Kualitas Aset

Berikut ini adalah tabel Rasio Kualitas Aset PT Bank Sumsel Babel Cabang Baturaja tahun 2016 s.d. 2018 :

Tabel Rasio Kualitas Aktiva

PT Bank Sumsel Babel Cabang Baturaja

Tahun 2016 s.d. 2018 (dalam jutaan rupiah)

\begin{tabular}{|l|c|c|c|}
\hline \multicolumn{1}{|c|}{ Keterangan } & Tahun 2016 & Tahun 2017 & Tahun 2018 \\
\hline $\begin{array}{l}\text { Aset produktif yang } \\
\text { diklasifikasikan }\end{array}$ & 2.442 & 4.476 & 2.442 \\
\hline Total aset produktif & 1.500 & 2.701 & 2.316 \\
\hline \%KAP & $1,62 \%$ & $1,65 \%$ & $1,05 \%$ \\
\hline Rata-rata & $1,44 \%$ & & \\
\hline
\end{tabular}

Sumber: data yang diolah, 2019

$>\quad$ Rasio Efisiensi Operasional

Berikut ini adalah tabel Rasio Efisiensi Operasional PT Bank Sumsel Babel Cabang Baturaja tahun 2016 s.d. 2018 :

Tabel Rasio Efisiensi Operasional

PT Bank Sumsel Babel Cabang Baturaja

Tahun 2016 s.d. 2018 (dalam jutaan rupiah)

\begin{tabular}{|l|l|l|l|}
\hline \multicolumn{1}{|c|}{ Keterangan } & \multicolumn{1}{c|}{ Tahun 2016 } & \multicolumn{1}{c|}{ Tahun 2017 } & \multicolumn{1}{c|}{ Tahun 2018} \\
\hline Biaya operasional & 18.707 & 20.067 & 31.039 \\
\hline $\begin{array}{l}\text { Pendapatan } \\
\text { operasional }\end{array}$ & 43.240 & 49.452 & 51.192 \\
\hline$\%$ BOPO & $43,26 \%$ & $40,57 \%$ & $60,63 \%$ \\
\hline Rata-rata & $48,15 \%$ & & \\
\hline
\end{tabular}

Sumber : Data yang diolah, 2019

2) Perspektif Pelanggan

> Market share
Berikut ini adalah tabel Market SharePT Bank Sumsel Babel Cabang Baturaja tahun 2016 s.d. 2018 : 
Tabel Market Share

PT Bank Sumsel Babel

Cabang Baturaja

Tahun 2016 s.d. 2018

\begin{tabular}{|c|c|c|}
\hline No & Tahun & Market Share (\%) \\
\hline 1 & 2016 & 98,01 \\
\hline 2 & 2017 & 99,12 \\
\hline 3 & 2018 & 98,02 \\
\hline \multicolumn{2}{|c|}{ Rata-rata } & 98,38 \\
\hline
\end{tabular}

Sumber : Data yang diolah, 2019

$>$ Customer Acquisition

Berikut ini adalah tabel Customer Acquisition PT Bank Sumsel Babel Cabang Baturaja tahun 2016 s.d. 2018:

\section{Tabel Customer Acquisition \\ PT Bank Sumsel Babel Cabang Baturaja Tahun 2017 dan 2018}

\begin{tabular}{|c|c|c|}
\hline No & Tahun & $\begin{array}{c}\text { Customer } \\
\text { Acquisition (\%) }\end{array}$ \\
\hline 1 & 2017 & 7,18 \\
\hline 2 & 2018 & 7,11 \\
\hline \multicolumn{2}{|c|}{ Rata-rata } & 7,14 \\
\hline
\end{tabular}

Sumber : Data yang diolah, 2019

\section{3) Perspektif Proses Bisnis Internal}

Berikut ini adalah tabel Service Error Rate PT Bank Sumsel Babel
Cabang Baturaja tahun 2016 s.d. 2018:

\section{Tabel Service Error Rate \\ PT Bank Sumsel Babel Cabang Baturaja Tahun 2016 s.d. 2018}

\begin{tabular}{|c|c|c|}
\hline No & Tahun & $\begin{array}{c}\text { Service Error Rate } \\
(\%)\end{array}$ \\
\hline 1 & 2016 & 25,00 \\
\hline 2 & 2017 & 75,00 \\
\hline 3 & 2018 & 85,71 \\
\hline \multicolumn{2}{|c|}{ Rata-rata } & 61,90 \\
\hline
\end{tabular}

Sumber : Data yang diolah, 2019

$>$ Perspektif Pembelajaran dan Pertumbuhan

Berikut ini adalah perhitungan Retensi Karyawan PT Bank Sumsel Babel Cabang Baturaja tahun 2016 s.d. 2018 :

Retensi Karyawan

$=\frac{\text { Jumlah Karyawan Keluar }}{\text { Total Jumlah Karyawan }} \times 100 \%$

$=\frac{1}{20} \times 100 \%=5 \%$

$>$ Keseluruhan Perspektif

Berikut ini adalah keseluruhan hasil perhitungan keseluruhan Perspektif dalam Balance Scorecard di PT Bank Sumsel Babel Cabang Baturaja tahun 2016 s.d. 2018

Tabel Hasil Perhitungan Keseluruhan Perspektif PT Bank Sumsel Babel Cabang Baturaja

Tahun 2016 s.d. 2018

\begin{tabular}{|l|l|c|c|}
\hline No & \multicolumn{1}{|c|}{ Indikator } & Standar & Hasil Perhitungan \\
\hline 1 & Return On Assets (ROA) & Baik & 8,58 \\
\hline 2 & Capital Adequency Ratio (CAR) & Baik & 20,46 \\
\hline 3 & Loan to Deposit Ratio (LDR) & Kurang Baik & 1,41 \\
\hline 4 & Kualitas Aset Produktif (KAP) & Baik & 1,44 \\
\hline 5 & Efesiensi Operasional (BOPO) & Baik & 48,15 \\
\hline 6 & Market Share & Baik & 3,00 \\
\hline 7 & Customer Acquisition & Kurang Baik & 1,00 \\
\hline 8 & Service Error Rate & Cukup Baik & 2,00 \\
\hline 9 & Retensi Karyawan & Cukup Baik & 2,00 \\
\hline
\end{tabular}

Sumber : Data yang diolah, 2019 
E. KESIMPULAN DAN SARAN

1) Kesimpulan

Hasil

penelitian

dan

pembahasan dari penilaian kinerja PT

Bank Sumsel Babel Cabang Baturaja

menggunakan Balanced Scorecard

menunjukkan bahwa secara

keseluruhan kinerja PT Bank Sumsel

Babel Cabang Baturaja termasuk kategori cukup. Sedangkan apabila dilihat dari masing-masing perspektif dapat dijelaskan sebagai berikut:

Dilihat dari perspektif keuangan, kinerja perusahaan tercapai hasil keseluruhan sudah cukup baik. Ada lima rasio yang digunakan dalam Perspektif Keuangan (Rasio Rentabilitas, Rasio Permodalan, Rasio Likuiditas, Rasio Kualitas Aset, Rasio Efisiensi Operasional).Rasio RentabilitasPT Bank Sumsel Babel Cabang Baturaja pada tahun 2018 menunjukkan hasil Return On Assets (ROA) sebesar $8,58 \%$ termasuk dalam kategori baik. Rasio Permodalan menunjukkan hasil Capital Adequency Ratio (CAR) sebesar $20,46 \%$ termasuk dalam kategori baik. Namun, Rasio Likuiditas menunjukkan hasil Loan to Deposit Ratio (LDR) sebesar $1,41 \%$ yang dikategorikan kurang baik yang mana perusahaan memiliki aset lancar yang berlebih yang membuat persentase likuiditas perusahaan menjadi terlalu tinggi. Rasio Kualitas Aset menunjukkan hasil yang baik untuk Kualitas Aset Produktif (KAP). Untuk Kualitas Aset Produktif (KAP) yang dicapai perusahaan pada tahun 2018 adalah 1,44\% termasuk kategori baik, dan di dalam Rasio Efesiensi Operasional menunjukkan hasil yang baik untuk

Biaya
Operasional/Pendapatan

Opersional (BOPO) yang dicapai perusahaan tahun 2018 adalah $48,15 \%$.

Perspektif Pelanggan. Dilihat dari Perspektif Pelanggan, kinerja perusahaan termasuk kategori baik. Dalam Perspektif Pelanggan digunakan tolak ukur Market Share dan Customer Acquisition. Market Share yang dicapai perusahaan mencapai nilai 3 yang termasuk kategori baik, Sedangkan yang termasuk Customer Acquisition mencapai nilai 1 dalam kategori kurang baik. Hal ini menggambarkan bahwa PT Bank Sumsel Babel Cabang Baturaja belum sepenuhnya berhasil dalam memenuhi kebutuhan nasabah seperti syarat-syarat yang mudah dalam pengajuan kredit dan pelayanan yang cepat kepada nasabah. Dan juga promosi serta iklan yang dilakukan bank belum cukup efektif dalam menarik nasabah baru.

Perspektif Proses Bisnis Internal. Dilihat dari Perspektif Proses Bisnis Internal, kinerja bank termasuk kategori cukup baik. Dalam Perspektif Proses Bisnis Internal digunakan tolak ukur Service Error Rate. Dari hasil pengukuran menunjukkan Service Error Rate PT Bank Sumsel Babel Cabang Baturaja pada tahun 2018 mencapai nilai 2 yang termasuk dalam kategori cukup baik, dimana bank telah merespon dengan baik dan selalu berusaha memperbaiki setiap kesalahan yang terjadi.

Perspektif Pembelajaran dan

Pertumbuhan. Dilihat dari

Perspektif Pembelajaran dan Pertumbuhan. Kinerja bank termasuk kategori cukup baik. 
Dalam Perspektif Pembelajaran dan Pertumbuhan digunakan tolak ukur Retensi Karyawan. Retensi Karyawan yang dicapai PT Bank Sumsel Babel Cabang Baturaja pada tahun 2018 adalah mencapai nilai 2 yang termasuk dalam kategori cukup baik, hal ini dikarenakan perusahaan telah memenuhi kebutuhan pada karyawan.

\section{2) Saran}

Berdasarkan kesimpulan di atas, maka penulis memberikan saran sebagai berikut :

PT Bank Sumsel Babel Cabang Baturaja harus dapat meningkatkan dan mengendalikan tingkat likuiditas perusahaan agar tidak terlalu besar dan terlalu kecil.

> PT Bank Sumsel Babel Cabang Baturaja harus dapat meningkatkan lagi pelayanaan jasa yang diberikan kepada nasabah melalui berbagai produk yang tersedia.

> PT Bank Sumsel Babel Cabang Baturaja harus lebih berhati-hati dalam tingkat pelayanan kesalahan yang diberikan.

PT Bank Sumsel Babel Cabang Baturaja harus lebih berusaha dalam mempertahankan karyawan yang diminati atau karyawan yang kinerjanya lebih bagus, agar dapat membantu mengembangkan keberhasilan bank.

\section{DAFTAR PUSTAKA}

Abdul, Achmad Fakhri. 2009. Sistem Pengendalian Manajemen.Edisi Revisi. UPP STIM YKPN. Yogyakarta.

Hansen dan Mowen. 2009. Akuntansi Manajerial. Edisi Kedelapan. Salemba Empat. Jakarta.

Kaplan dan Norton. 2010. Balanced Scorecard: Menerapkan Strategi Menjadi Aktif.Erlangga. Jakarta.

Mulyadi. 2010. Sistem Perencanaan dan Pengendalian Manajemen Sistem Pelipatganda Kinerja Keuangan.Edisi Ketiga. Salemba Empat. Jakarta.

Sony, dkk. 2010. Petunjuk Praktis Penyusunan Balanced Scorecard.Cetakan Kelima. PT Gramedia Pustaka Utama. Jakarta.

Sugiyono. 2010. Metode Penelitian Bisnis. Alfabeta.Bandung.

Veithzal dan Arviyan. 2010.Islamic Banking : Sistem Bank Islam. Edisi Kesatu. Bumi Aksara. Jakarta. 